\title{
Cost-Effective Applications of Power Factor Correction for Nonlinear Loads
}

\author{
Ahmed Faheem Zobaa, Senior Member, IEEE
}

\begin{abstract}
The objective of this paper is to propose a new approach for designing passive $L C$ compensators by using the penalty function method as an optimization tool. The performance of the cost-effective passive $L C$ compensator for a constant load depends on the appropriate inductor and capacitor selection. Several design methods are reviewed and a novel design methodology is proposed in this paper. By using the proposed method, the designer can quickly find appropriate parameter values to meet the desired circuit performance. Simulated results show that an appropriate combination of the inductor and capacitor selected by the proposed method can meet the desired power-quality requirement. Different cases of design examples are shown in this paper to verify the performance of the proposed design methodology.
\end{abstract}

Index Terms-Harmonics, power factor, reactive power.

\section{NOMENCLATURE}

$\mathrm{R}_{\mathrm{LK}}, \mathrm{X}_{\mathrm{LK}}$ Load resistance and reactance at harmonic number K (in ohms).

$\mathrm{G}_{\mathrm{LK}}, \mathrm{B}_{\mathrm{LK}} \quad$ Load conductance and susceptance at harmonic number K (in ohms).

$\mathrm{R}_{\mathrm{TK}}, \mathrm{X}_{\mathrm{TK}} \quad$ Thevenin resistance and reactance at harmonic number K (in ohms).

$\mathrm{X}_{\mathrm{L}}, \mathrm{X}_{\mathrm{C}} \quad$ Fundamental inductive and capacitive reactance of the compensator (in ohms).

$\mathrm{R} \quad$ Resistance of the compensator reactor $(\Omega)$.

$\mathrm{I}_{\mathrm{S}}^{o} \quad$ Supply current without compensation (in amps).

IS RMS supply current with compensation (in amps).

I SK Supply current at harmonic number K (in amps).

I LK Load harmonic current (in amperes).

$\mathrm{I}_{\mathrm{CK}} \quad$ Capacitor current at harmonic number K (in amperes).

$\mathrm{I}_{\mathrm{C}} \quad \mathrm{RMS}$ capacitor current with compensation (in amperes).

$\mathrm{V}_{\mathrm{L}} \quad \mathrm{RMS}$ value of load voltage (in volts).

$\mathrm{V}_{\mathrm{SK}} \quad$ Supply voltage at harmonic number K (in volts).

$\mathrm{V}_{\mathrm{LK}} \quad$ Load voltage at harmonic number $\mathrm{K}$ (in volts).

$\mathrm{V}_{\mathrm{CR}} \quad$ Capacitor rated rms voltage (in volts).

$\mathrm{V}_{\mathrm{C}} \quad \mathrm{RMS}$ capacitor voltage with compensation (in volts).

$\mathrm{V}_{\mathrm{CC}} \quad$ Crest capacitor voltage with compensation (in volts).

PF Load power factor (in per unit).

Manuscript received April 8, 2003; revised May 31, 2003. Paper no. TPWRD00152-2003.

The author is with the Electrical Power and Machines Department, Faculty of Engineering, Cairo University, Giza 12613, Egypt (e-mail: a.zobaa@eng.cu.edu.eg).

Digital Object Identifier 10.1109/TPWRD.2004.835034
$\mathrm{d}_{\mathrm{PF}} \quad$ Load displacement power factor (in per unit). $\eta \quad$ Network transmission efficiency (in percentage). TL Loss in Thevenin resistance (in kilowatts).

\section{INTRODUCTION}

$\mathbf{P}$ OWER-ELECTRONIC loads are rapidly growing in number. Due to their nonlinear nature, they are the major sources of harmonics in electric utility networks.

From the utility customer's point of view, harmonics can be classified as those generated by the customer load itself, which should be compensated locally; and those which are caused by other utility customers whose nonlinear loads have created voltage distortions at a common voltage bus. Distorted bus voltage then causes harmonic currents in neighboring linear compensated loads, particularly if series resonance occurs between Thevenin impedance and compensated load. A customer with such a load needs to minimize the harmonic line currents while simultaneously using a compensator to maintain a high power factor.

Several approaches [1]-[8] discuss the different parameters affecting the economic feasibility of power factor correction. It is shown that the specific costs of the transmission and compensation elements as well as those of the electrical energy and power losses have a decisive influence on the achievable overall economic saving. In some approaches [9]-[13] on the subject to achieving the maximum possible power factor, the effect of harmonic voltages and currents on capacitor and inductor cost has been ignored.

An optimization method for the proper selection of the $L C$ compensator values taking into account cost constraints is described for nonlinear loads [14]. It uses the nonlinear model of the loads, which is neglected in [15]. The solution will be obtained with an optimization algorithm based on the reduced gradient technique which will locate maximum power factors by searching along the constant-cost power factor ridges, for the point where the gradient of the transmission loss is zero.

This paper will show that the static $L C$ compensator needs to be optimally designed during the compensation of nonlinear loads. The compensator must be designed to meet minimum requirements in terms of power factor and harmonic distortion of the current ITHD and the voltage VTHD while, at the same time, minimizing its total cost. It is assumed that both the equivalent source and load are considered to generate harmonics. Also, it is assumed that the load harmonics are not sufficiently serious to suggest tuned filters, but when combined with source harmonics, the use of a pure capacitive compensator would degrade power factor and overload equipment. Consequently, $L C$ compensators are selected [16]. The basic approach to power factor 


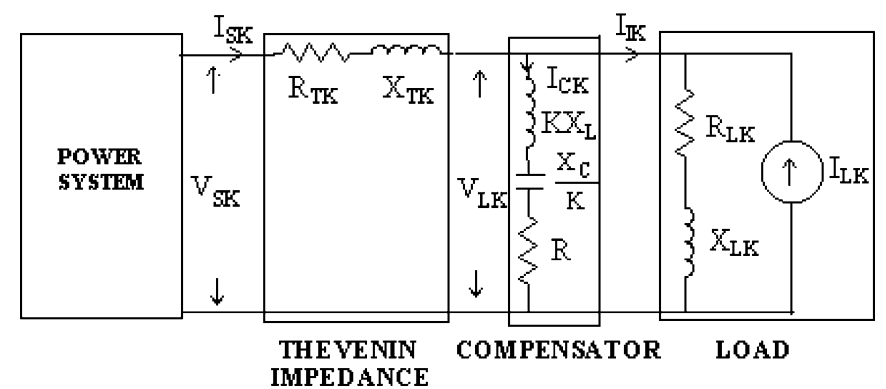

Fig. 1. Single-phase equivalent circuit for $K$ th harmonic with shunt $L C$ compensator.

correction is first explained, and the cost function expression and analysis are discussed. Then, the optimization algorithm using the penalty function method is presented. Finally, the simulation results are discussed and compared with other published techniques.

\section{BASIC APPROACH TO POWER-FACTOR CORRECTION}

Fig. 1 is a single-phase equivalent circuit of a bus with $L C$ compensator, experiencing VTHD at harmonic order $K$ because of a voltage source $V_{S} K$ and harmonic current sources within the load itself $I_{L} K$. The series reactor $X_{L}$ has been added to minimize VTHD while $X_{C}$ has been altered to maintain the power factor at a desired level.

The Thevenin voltage source representing the utility supply and the harmonic current source representing the nonlinear load is

and

$$
\mathrm{v}_{\mathrm{S}}(\mathrm{t})=\sum_{\mathrm{K}} \mathrm{v}_{\mathrm{SK}}(\mathrm{t})
$$

$$
\mathrm{i}_{\mathrm{LK}}(\mathrm{t})=\sum_{\mathrm{K}} \mathrm{i}_{\mathrm{LK}(\mathrm{t})}
$$

where $K$ is the order of harmonic present. The $K$ th harmonic Thevenin source and load impedances are

$$
\text { and } \quad \begin{aligned}
\mathrm{Z}_{\mathrm{TK}} & =\mathrm{R}_{\mathrm{TK}}+\mathrm{j} \mathrm{X}_{\mathrm{TK}} \\
\mathrm{Z}_{\mathrm{LK}} & =\mathrm{R}_{\mathrm{LK}}+\mathrm{j} \mathrm{X}_{\mathrm{LK}}
\end{aligned}
$$

or

$$
\mathrm{Y}_{\mathrm{LK}}=\mathrm{G}_{\mathrm{LK}}-\mathrm{j} \mathrm{B}_{\mathrm{LK}} \cdot
$$

Also, the $K$ th harmonic LC compensator impedance is

$$
\mathrm{Z}_{\mathrm{CK}}=\mathrm{R}+\mathrm{j}\left(\mathrm{KX}_{\mathrm{L}}-\frac{\mathrm{X}_{\mathrm{C}}}{\mathrm{K}}\right)
$$

Finally, this model, Fig. 1, is adequate where VTHD is less than $10 \%$ [17].

From the first principle, the following equation can be obtained:

$$
\mathrm{V}_{\mathrm{SK}}=\mathrm{Z}_{\mathrm{TK}} * \mathrm{I}_{\mathrm{SK}}+\left(\mathrm{I}_{\mathrm{SK}}-\mathrm{I}_{\mathrm{LK}}\right) * \frac{\left(\mathrm{Z}_{\mathrm{CK}} * \mathrm{Z}_{\mathrm{LK}}\right)}{\left(\mathrm{Z}_{\mathrm{CK}}+\mathrm{Z}_{\mathrm{LK}}\right)}
$$

By simplification and substituting the expressions for $Z_{T K}$, $Z_{C K}$, and $Z_{L K}$ in the above equation, we can get expressions for $I_{S K}, I_{C K}$, and $V_{L K}$.
The approach will be to minimize the compensator cost by adjusting $X_{C}$ and $X_{L}$ while keeping the power factor constant. The compensator cost is defined as

$$
\mathrm{C}=\mathrm{U}_{\mathrm{C}} * \mathrm{~S}_{\mathrm{C}}+\mathrm{U}_{\mathrm{L}} * \mathrm{~S}_{\mathrm{L}}
$$

where $U_{C}, U_{L}=$ unit cost of capacitor and inductor (\$/kVA), and considered to be constant parameters.

For capacitors and reactors, volt-ampere ratings are defined as [18]

$$
\mathrm{S}_{\mathrm{C}}=\left[\sum_{\mathrm{K}} \mathrm{I}_{\mathrm{CK}} * \frac{\mathrm{X}_{\mathrm{C}}}{\mathrm{K}}\right]\left[\sum_{\mathrm{K}} \mathrm{I}_{\mathrm{CK}}^{2}\right]^{\frac{1}{2}} \mathrm{kVA}
$$

and

$$
\mathrm{S}_{\mathrm{L}}=\left[\sum_{\mathrm{K}} \mathrm{I}_{\mathrm{CK}} * \mathrm{~K} * \mathrm{X}_{\mathrm{L}}\right]\left[\sum_{\mathrm{K}} \mathrm{I}_{\mathrm{CK}}^{2}\right]^{\frac{1}{2}} \mathrm{kVA}
$$

where the compensator current $I_{C K}$ is given

$$
\begin{aligned}
\mathrm{I}_{\mathrm{CK}}= & \frac{\mathrm{V}_{\mathrm{SK}}\left(\mathrm{R}_{\mathrm{SK}}+\mathrm{j} \mathrm{X}_{\mathrm{LK}}\right)-\mathrm{I}_{\mathrm{LK}}\left(\mathrm{R}_{\mathrm{TLK}}+\mathrm{j} \mathrm{X}_{\mathrm{TLK}}\right)}{\mathrm{A}_{\mathrm{IK}}+\mathrm{jA}_{\mathrm{JK}}} \\
\mathrm{R}_{\mathrm{TLK}}= & \mathrm{R}_{\mathrm{TK}} * \mathrm{R}_{\mathrm{LK}}-\mathrm{X}_{\mathrm{TK}} * \mathrm{X}_{\mathrm{LK}} \\
\mathrm{X}_{\mathrm{TLK}}= & \mathrm{R}_{\mathrm{TK}} * \mathrm{X}_{\mathrm{LK}}+\mathrm{X}_{\mathrm{LK}} * \mathrm{R}_{\mathrm{LK}} \\
\mathrm{A}_{\mathrm{IK}}= & \mathrm{R}_{\mathrm{TLK}}+\mathrm{R}\left(\mathrm{R}_{\mathrm{LK}}+\mathrm{R}_{\mathrm{TK}}\right)-\left(\mathrm{X}_{\mathrm{LK}}+\mathrm{X}_{\mathrm{TK}}\right) \\
& \times\left(\mathrm{KX} \mathrm{X}_{\mathrm{L}}-\frac{\mathrm{X}_{\mathrm{C}}}{\mathrm{K}}\right) \\
\mathrm{A}_{\mathrm{JK}}= & \mathrm{X}_{\mathrm{TLK}}+\mathrm{R}\left(\mathrm{R}_{\mathrm{LK}}+\mathrm{X}_{\mathrm{TK}}\right)+\left(\mathrm{R}_{\mathrm{LK}}+\mathrm{R}_{\mathrm{TK}}\right) \\
& \times\left(\mathrm{KX}_{\mathrm{L}}-\frac{\mathrm{X}_{\mathrm{C}}}{\mathrm{K}}\right) .
\end{aligned}
$$

In (7) and (8), the harmonic voltages are added linearly in the first summation to emphasize the effect of peak (as opposed to rms) voltage on insulation cost.

The compensated $P F$ at the load is given as

$$
\begin{aligned}
\mathrm{PF} & =\frac{\mathrm{P}_{\mathrm{L}}}{\mathrm{V}_{\mathrm{L}} \mathrm{I}_{\mathrm{S}}} \\
& =\frac{\sum \mathrm{G}_{\mathrm{LK}} \mathrm{V}_{\mathrm{LK}}^{2}}{\sqrt{\sum \mathrm{I}_{\mathrm{SK}}^{2} \sum \mathrm{V}_{\mathrm{LK}}^{2}}} \\
\mathrm{I}_{\mathrm{SK}} & =\frac{\mathrm{V}_{\mathrm{SK}}(\mathrm{AR}+\mathrm{jR})+\mathrm{I}_{\mathrm{LK}} \mathrm{CR}}{\mathrm{A}_{\mathrm{IK}}+\mathrm{j} \mathrm{A}_{\mathrm{JK}}} \\
\mathrm{V}_{\mathrm{LK}} & =\frac{\mathrm{V}_{\mathrm{SK}}(\mathrm{CR})-\mathrm{I}_{\mathrm{LK}}(\mathrm{DR} * \mathrm{ER})}{\mathrm{A}_{\mathrm{IK}}+\mathrm{j} \mathrm{A}_{\mathrm{JK}}}
\end{aligned}
$$

where

$$
\begin{aligned}
\mathrm{AR} & =\mathrm{R}+\mathrm{R}_{\mathrm{LK}} \\
\mathrm{BR} & =\left(\mathrm{X}_{\mathrm{LK}}+\mathrm{KX}_{\mathrm{L}}-\frac{\mathrm{X}_{\mathrm{C}}}{\mathrm{K}}\right) \\
\mathrm{CR} & =\mathrm{R}_{\mathrm{CLK}}+\mathrm{j} \mathrm{X}_{\mathrm{CLK}} \\
\mathrm{DR} & =\mathrm{Z}_{\mathrm{CK}} \\
\mathrm{ER} & =\mathrm{R}_{\mathrm{TLK}}+\mathrm{j} \mathrm{X}_{\mathrm{TLK}} \\
\mathrm{R}_{\mathrm{CLK}} & =\mathrm{RR}_{\mathrm{LK}}-\mathrm{X}_{\mathrm{LK}}\left(\mathrm{KX}_{\mathrm{L}}-\frac{\mathrm{X}_{\mathrm{C}}}{\mathrm{K}}\right) \\
\mathrm{X}_{\mathrm{CLK}} & =\mathrm{RX}_{\mathrm{LK}}+\mathrm{R}_{\mathrm{LK}}\left(\mathrm{KX}_{\mathrm{L}}-\frac{\mathrm{X}_{\mathrm{C}}}{\mathrm{K}}\right) .
\end{aligned}
$$

The additional constraints involved are the effect of supply frequency on the ac resistance, the compensator values, which 
would create resonant conditions and the manufacturer's standard values for power shunt capacitors.

\section{A. Effect of Supply Frequency on the AC Resistance}

In most power systems, one can generally assume that the resistance does not change significantly when studying the effects of harmonics less than the ninth [17]. In this study, it is assumed that

$$
\mathrm{R}_{\mathrm{TK}}=\mathrm{R}_{\mathrm{T}} \quad \text { and } \quad \mathrm{R}_{\mathrm{LK}}=\mathrm{R}_{\mathrm{L}}
$$

where $R_{T}$ is the resistance of the Thevenin impedance at the fundamental frequency, and $R_{L}$ is the resistance of the load at the fundamental frequency.

\section{B. Resonance Constraint}

The expected impedance seen from the Thevenin source is given by

$$
\mathrm{Z}=\mathrm{Z}_{\mathrm{TK}}+\frac{\left(\mathrm{R}_{\mathrm{CLK}}+\mathrm{j} \mathrm{X}_{\mathrm{CLK}}\right)}{\left(\mathrm{Z}_{\mathrm{LK}}+\mathrm{Z}_{\mathrm{CK}}\right)}
$$

The resonance peaks can be obtained by setting the imaginary part of (14) to zero, resulting in a quadratic equation in $X_{C}$ and $X_{L}$ for any given harmonic order $K$

$$
\alpha_{1}\left(\mathrm{KX}_{\mathrm{L}}-\frac{\mathrm{X}_{\mathrm{C}}}{\mathrm{K}}\right)^{2}+\alpha_{2}\left(\mathrm{KX}_{\mathrm{L}}-\frac{\mathrm{X}_{\mathrm{C}}}{\mathrm{K}}\right)+\alpha_{3}=0
$$

where

$$
\begin{aligned}
& \alpha_{1}=\mathrm{X}_{\mathrm{TK}}+\mathrm{X}_{\mathrm{LK}} \\
& \alpha_{2}=\mathrm{R}_{\mathrm{LK}}^{2}+\mathrm{X}_{\mathrm{LK}}^{2}+2 \mathrm{X}_{\mathrm{LK}} \mathrm{X}_{\mathrm{TK}} \\
& \alpha_{3}=\mathrm{R}^{2} \mathrm{X}_{\mathrm{LK}}+\mathrm{X}_{\mathrm{TK}}\left[\left(\mathrm{R}+\mathrm{R}_{\mathrm{LK}}\right)^{2}+\mathrm{X}_{\mathrm{LK}}^{2}\right] .
\end{aligned}
$$

The precalculated compensator values for series resonance, by taking the solution of (15) where the square root of the discriminant is positive, are used to subdivide the entire search region into smaller regions. In each region, the total minimums are identified leading to the eventual identification of the global minimum of any of the functions. This makes the optimal LC compensator value not a part of (15).

\section{Standard Ratings of the Capacitors}

IEEE Std. 18-1992 [19] shows the voltage and reactive power ratings of the capacitors. Each value of the kvar ratings $Q_{C}$ of the particular voltage is used to calculate the corresponding value of $X_{C i}$. This value is then substituted into (16) to become one variable equation in $X_{L}$,

Then, the problem becomes

$$
\begin{array}{lc}
\text { Minimize } & \mathrm{C}\left(\mathrm{X}_{\mathrm{Ci}}, \mathrm{X}_{\mathrm{L}}\right) \\
\text { Subject to: } & \mathrm{PF}\left(\mathrm{X}_{\mathrm{Ci}}, \mathrm{X}_{\mathrm{L}}\right) \geq 90 \%, \\
& \mathrm{X}_{\mathrm{Ci}} \text { and } \mathrm{X}_{\mathrm{L}} \text { are not a part of }(15) .
\end{array}
$$

The objective function and constraints are complicated to be solved directly. Hence, an iterative method is needed to generate

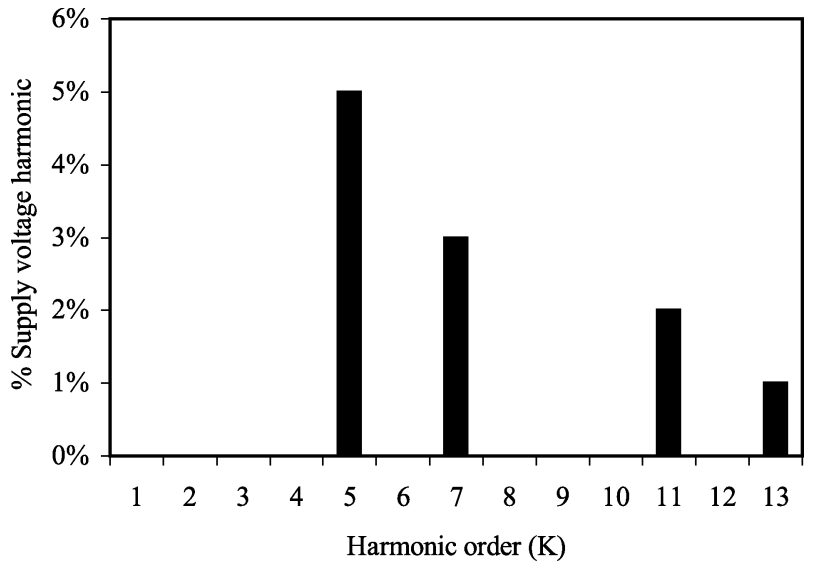

Fig. 2. Harmonic contents of the supply voltage for cases 1, 3, and 5 .

the solution. From the experience, the penalty function method is chosen since it requires fewer steps and function evaluations [20], [21].

Penalty function methods transform the basic optimization problem into an alternative formulation such that numerical solutions are sought by solving a sequence of unconstrained minimization problems. The search algorithm [22] is described in Appendix A.

In the optimization process, the resistance of the compensator reactor has been neglected due to its small value with respect to its fundamental reactance [15].

\section{Simulated EXAmples AND Discussion}

Five cases of an industrial plant were simulated using the optimization method. The numerical data were primarily taken from an example in [18] where the inductive three-phase load of $5100 \mathrm{~kW}$ and $4965 \mathrm{kVAR}$ is connected to a supply bus with voltage $4160 \mathrm{~V}$ and $60-\mathrm{Hz}$ frequency. The short-circuit MVA is 150 MVA for cases 1, 2, and 5. Also, it is 80 MVA for cases 3 and 4 . The system data for equivalent single-phase mode are

$$
\begin{aligned}
\text { Thevenin impedance } & =0.01154+0.1152 \Omega \text { for } 150 \mathrm{MVA} \\
\text { Thevenin impedance } & =0.02163+0.2163 \Omega \text { for } 80 \mathrm{MVA} \\
\text { Load impedance } & =1.7421+1.696 \Omega .
\end{aligned}
$$

Either $U_{L}$ or $U_{C}$ is $2 \$ / \mathrm{kVA}$ except in case $5 U_{L}$ is $4 \$ / \mathrm{kVA}$. 4160-V capacitors are used.

Figs. 2-4 show harmonic contents, arbitrarily selected, of the supply voltage, and the load current.

The advantages of the presented method are explicitly demonstrated in the following tables.

Table I shows that a lower short-circuit capacity, cases 3 and 4 , corresponds to a lower cost at the same power factor compared with cases 1 and 2 . This to be expected since with higher Thevenin impedance, less harmonic current will flow into the compensated load.

Also, an additional harmonic content, cases 2 and 4, results in a cost increase for obtaining the same power factor compared with cases 1 and 2 . This is caused by the increase in compensator rating due to the additional harmonics. 


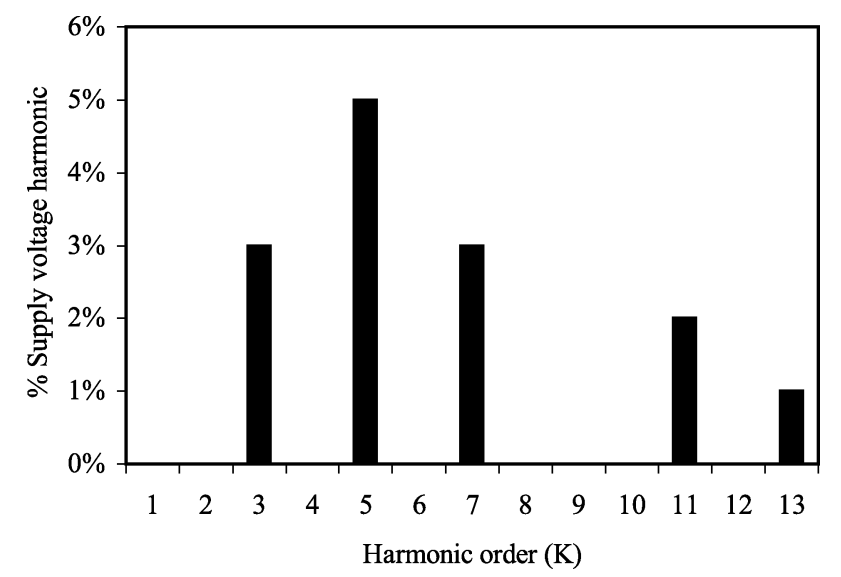

Fig. 3. Harmonic contents of the supply voltage for cases 2 and 4.

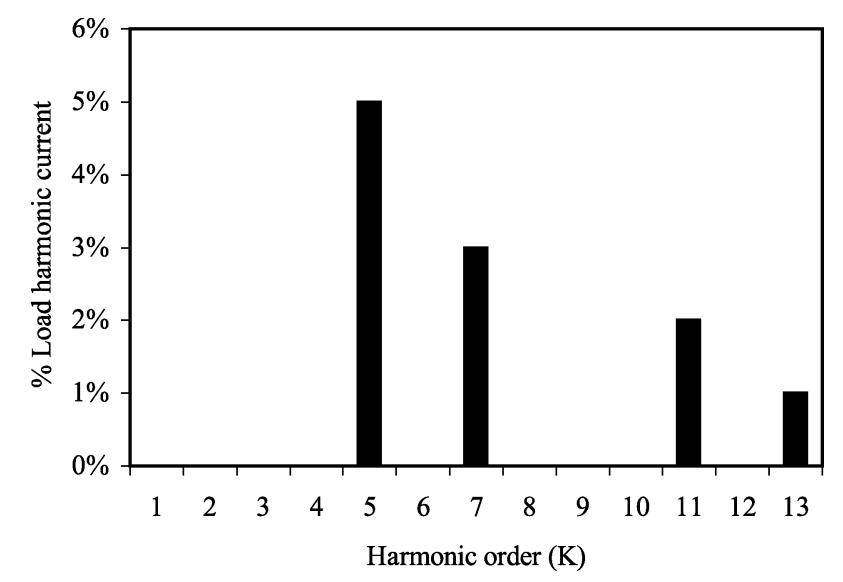

Fig. 4. Harmonic contents of the load current for all cases.

TABLE I

SIMULATED RESUlTS FOR DIFFERENT CASES UNDER STUDY

\begin{tabular}{l|c|c|c|c}
\hline \hline CASE & $\mathrm{Q}_{\mathrm{C}}$ & $\mathrm{X}_{\mathrm{L}}^{*}(\Omega)$ & $\mathrm{PF}(\%)$ & $\mathrm{C}(\$)$ \\
\hline 1 & 2400 & 0.7015 & 90.60 & 6632 \\
\hline 2 & 2250 & 1.0896 & 90.00 & 7463 \\
\hline 3 & 2550 & 0.2948 & 90.26 & 6154 \\
\hline 4 & 2250 & 1.0266 & 90.00 & 7116 \\
\hline 5 & 2700 & 0.3038 & 90.34 & 7438 \\
\hline \hline
\end{tabular}

Finally, the case of increasing the unit cost of the reactor, case 5 , with the same conditions as case 1 , has a power factor which requires a higher compensator cost to obtain the same power factor, reflecting the additional reactor cost.

The presented method results in lower supply current, lower transmission loss, higher transmission efficiency, and higher displacement power factor than the uncompensated case. So, the main advantage of the presented method consists in less harmonic power in secondary cables, lines, and switchgear owned by the end user. Tables II and III show the supply current, the transmission loss, the transmission efficiency, and the displacement power factor without and with compensation for different cases under study.

Table IV shows the harmonic contents of the supply current as a percentage of the fundamental current and ITHD with compensation for the different cases under study.
TABLE II

SUPPLY CURRENT, TRANSMISSION LOSS, TRANSMISSION EFFICIENCY, AND DISPLACEMENT POWER FACTOR WITHOUT COMPENSATION

\begin{tabular}{l|c|c|c|c}
\hline \hline CASE & $\mathrm{I}_{\mathrm{S}}^{o}(\mathrm{~A})$ & $\mathrm{TL}(\mathrm{kW})$ & $\eta(\%)$ & $\mathrm{dPF}(\%)$ \\
\hline 1 & 953.64 & 10.49 & 99.34 & 71.65 \\
\hline 2 & 953.72 & 10.50 & 99.34 & 71.65 \\
\hline 3 & 924.14 & 18.47 & 98.77 & 71.65 \\
\hline 4 & 924.22 & 18.48 & 98.77 & 71.65 \\
\hline 5 & 953.64 & 10.49 & 99.34 & 71.65 \\
\hline \hline
\end{tabular}

TABLE III

SupPly CurRent, Transmission LOSS, Transmission EFFICIENCY, AND DISPLACEMENT POWER FACTOR WITH COMPENSATION

\begin{tabular}{c|c|c|c|c}
\hline \hline CASE & $\mathrm{I}_{\mathrm{S}}(\mathrm{A})$ & $\mathrm{TL}(\mathrm{kW})$ & $\eta(\%)$ & $\mathrm{dPF}(\%)$ \\
\hline 1 & 764.59 & 6.75 & 99.59 & 91.14 \\
\hline 2 & 769.30 & 6.83 & 99.58 & 90.90 \\
\hline 3 & 755.45 & 12.34 & 99.22 & 91.19 \\
\hline 4 & 755.82 & 12.36 & 99.22 & 90.73 \\
\hline 5 & 767.77 & 6.80 & 99.59 & 92.30 \\
\hline \hline
\end{tabular}

TABLE IV

Harmonic CONTENTS of THE SuPPly CurRent as a PERCENTAGE OF THE FUNDAMENTAL CURRENT AFTER COMPENSATION

\begin{tabular}{c|c|c|c|c|c}
\hline \hline CASE & 1 & 2 & 3 & 4 & 5 \\
\hline$\% \mathrm{I}_{\mathrm{S} 3}$ & 0.0 & 9.66 & 0.0 & 8.52 & 0.0 \\
\hline$\% \mathrm{I}_{\mathrm{S} 5}$ & 8.66 & 7.39 & 13.40 & 6.56 & 19.79 \\
\hline$\% \mathrm{I}_{\mathrm{S} 7}$ & 4.03 & 3.84 & 4.15 & 3.42 & 5.53 \\
\hline$\% \mathrm{I}_{\mathrm{S} 11}$ & 2.32 & 2.35 & 1.91 & 2.09 & 2.46 \\
\hline$\% \mathrm{I}_{\mathrm{S} 13}$ & 1.13 & 1.15 & 0.88 & 1.03 & 1.13 \\
\hline$\% \mathrm{ITHD}$ & 9.89 & 13.02 & 14.18 & 11.52 & 20.72 \\
\hline \hline
\end{tabular}

TABLE V

Harmonic CONTENTS of THE LOAd Voltage AS A Percentage of THE FUNDAMENTAL VOLTAGE AFTER COMPENSATION

\begin{tabular}{c|c|c|c|c|c}
\hline \hline CASE & 1 & 2 & 3 & 4 & 5 \\
\hline$\% \mathrm{~V}_{\mathrm{L} 3}$ & 0.0 & 1.97 & 0.0 & 1.32 & 0.0 \\
\hline$\% \mathrm{~V}_{\mathrm{L} 5}$ & 3.91 & 4.33 & 0.83 & 4.18 & 1.54 \\
\hline$\% \mathrm{~V}_{\mathrm{L} 7}$ & 2.57 & 2.75 & 1.57 & 2.79 & 1.90 \\
\hline$\% \mathrm{~V}_{\mathrm{L} 11}$ & 1.88 & 1.99 & 1.49 & 2.22 & 1.54 \\
\hline$\% \mathrm{~V}_{\mathrm{L} 13}$ & 0.99 & 1.04 & 0.83 & 1.21 & 0.82 \\
\hline$\% \mathrm{VTHD}$ & 5.13 & 5.94 & 2.46 & 5.78 & 3.00 \\
\hline \hline
\end{tabular}

Table IV shows the harmonic contents of the load voltage as a percentage of the fundamental voltage and VTHD with compensation for the different cases under study.

IEEE Standard 519-1992 [23] lists the harmonic current limits based on the size of the load with respect to the size of the power system to which the load is connected. Also, it shows that the objectives of the nonlinear load harmonic current limits are to limit the maximum individual harmonic voltage to $3 \%$ of the fundamental voltage and the total harmonic distortion of the voltage to $5 \%$. Most of the resultant values, Tables IV and $\mathrm{V}$, come out well within standard limits. 
TABLE VI

SIMUlATED RESUltS FOR DIFFERENT CASES UNDER STUDY USING (18)

\begin{tabular}{l|c|c|c|c}
\hline \hline CASE & $\mathrm{Q}_{\mathrm{C}}$ & $\mathrm{X}_{\mathrm{L}}^{*}(\Omega)$ & $\mathrm{PF}(\%)$ & $\mathrm{C}(\$)$ \\
\hline 1 & 2700 & 0.3038 & 90.34 & 6758 \\
\hline 2 & 2400 & 0.8984 & 90.17 & 7805 \\
\hline 3 & 2550 & 0.2948 & 90.26 & 6154 \\
\hline 4 & 2250 & 1.0533 & 90.10 & 7169 \\
\hline 5 & 2700 & 0.3038 & 90.34 & 7438 \\
\hline \hline
\end{tabular}

TABLE VII

SuPPly CURRENT, TRANSMISSION LOSS, TRANSMISSION EFFICIENCY, AND DisPlaCEMENT POWER FACTOR WITH COMPENSATION USING (18)

\begin{tabular}{l|c|c|c|c}
\hline \hline CASE & $\mathrm{I}_{\mathrm{S}}(\mathrm{A})$ & $\mathrm{TL}(\mathrm{kW})$ & $\eta(\%)$ & $\mathrm{dPF}(\%)$ \\
\hline 1 & 767.77 & 6.80 & 99.59 & 92.30 \\
\hline 2 & 768.58 & 6.82 & 99.58 & 91.70 \\
\hline 3 & 755.45 & 12.34 & 99.22 & 91.19 \\
\hline 4 & 754.59 & 12.32 & 99.22 & 90.80 \\
\hline 5 & 767.77 & 6.80 & 99.59 & 92.30 \\
\hline \hline
\end{tabular}

TABLE VIII

TOTAL HARMONIC DisTORTIONS FOR DIFFERENT CASES UNDER STUDY USING (18)

\begin{tabular}{c|c|c|c|c|c}
\hline \hline CASE & 1 & 2 & 3 & 4 & 5 \\
\hline \% ITHD & 20.72 & 17.70 & 14.18 & 11.17 & 20.72 \\
\hline \% VTHD & 2.95 & 5.50 & 2.37 & 5.62 & 2.95 \\
\hline \hline
\end{tabular}

Now we test the $d P F$ as a constraint in the optimization problem. The compensated $d P F$ at the load is given as

$$
\mathrm{dPF}=\frac{\mathrm{P}_{\mathrm{L} 1}}{\mathrm{~V}_{\mathrm{L} 1} \mathrm{I}_{\mathrm{S} 1}}
$$

where $P_{\mathrm{L} 1}, V_{\mathrm{L} 1}$, and $I_{\mathrm{S} 1}$ are the fundamental components of the load power, the load voltage, and the supply current.

Then, the problem becomes

$$
\begin{array}{ll}
\text { Minimize } & \mathrm{C}\left(\mathrm{X}_{\mathrm{Ci}}, \mathrm{X}_{\mathrm{L}}\right) \\
\text { Subject to: } & \mathrm{dPF}\left(\mathrm{X}_{\mathrm{Ci}}, \mathrm{X}_{\mathrm{L}}\right) \geq 90 \%, \\
& \mathrm{X}_{\mathrm{Ci}} \text { and } \mathrm{X}_{\mathrm{L}} \text { are not a part of }(15) .
\end{array}
$$

The simulated results are explicitly demonstrated in Tables VI-VIII.

Comparison of the results shows that the general performance of the method, dPF, as a constraint, is satisfactory, providing improvement of the overall performance compared with Tables I, III, IV, and V.

The object of passive LC compensators is to reduce one or more harmonic orders (generally 5, 7, 11). Although cases 2 and 4 have a zero-sequence harmonic, the performance of the system with the suggested compensation is improved. Also, cases 2 and 4 need active filtering or neutral filtering beside the suggested compensation.
TABLE IX

Simulated Results fOR DifFERENT CASES UNDER STUDY USING (19)

\begin{tabular}{l|c|c|c|c}
\hline \hline CASE & $\mathrm{Q}_{\mathrm{C}}$ & $\mathrm{X}_{\mathrm{L}}^{*}(\Omega)$ & $\mathrm{PF}(\%)$ & $\mathrm{C}(\$)$ \\
\hline 1 & 2700 & 0.3038 & 90.34 & 6758 \\
\hline 2 & 2700 & 0.4421 & 90.64 & 7579 \\
\hline 3 & 2400 & 0.6708 & 90.64 & 6449 \\
\hline 4 & 2250 & 1.0533 & 90.10 & 7169 \\
\hline 5 & 2700 & 0.3038 & 90.34 & 7438 \\
\hline \hline
\end{tabular}

TABLE $\mathrm{X}$

SuPPly CURRENT, TRANSMISSION LOSS, TRANSMISSION EFFICIENCY, AND DiSPLACEMENT POWER FACTOR WITH COMPENSATION USING (19)

\begin{tabular}{l|c|c|c|c}
\hline \hline CASE & $\mathrm{I}_{\mathrm{S}}(\mathrm{A})$ & $\mathrm{TL}(\mathrm{kW})$ & $\eta(\%)$ & $\mathrm{dPF}(\%)$ \\
\hline 1 & 767.77 & 6.80 & 99.59 & 92.30 \\
\hline 2 & 765.02 & 6.75 & 99.59 & 92.72 \\
\hline 3 & 750.55 & 12.19 & 99.23 & 91.06 \\
\hline 4 & 754.59 & 12.32 & 99.22 & 90.80 \\
\hline 5 & 767.77 & 6.80 & 99.59 & 92.30 \\
\hline \hline
\end{tabular}

TABLE XI

TOTAL HARMONIC DISTORTIONS AND CAPACITOR LIMITS FOR DIFFERENT CASES UNDER STUdy USING (19)

\begin{tabular}{c|c|c|c|c|c}
\hline \hline CASE & 1 & 2 & 3 & 4 & 5 \\
\hline$\%$ ITHD & 20.72 & 20.81 & 8.39 & 11.17 & 20.72 \\
\hline$\%$ VTHD & 2.95 & 6.48 & 4.93 & 5.62 & 2.95 \\
\hline$\% \mathrm{~V}_{\mathrm{C}}$ & 103.41 & 106.38 & 157.82 & 140.20 & 103.41 \\
\hline$\% \mathrm{~V}_{\mathrm{CC}}$ & 112.34 & 123.19 & 255.83 & 225.40 & 112.34 \\
\hline \hline
\end{tabular}

Capacitors shall be capable of continuous operation provided that none of the following limitations are exceeded [19]: $V_{C}$ not exceeding 110 of $V_{C R}$, and $V_{C C}$ not exceeding $1.2 * \sqrt{2}$ of $V_{C R}$ including harmonics but excluding transients. To make the design method guarantee that the voltage across the capacitor will not exceed the permissible maximum level, the problem becomes

$$
\begin{array}{ll}
\text { Minimize } & \mathrm{C}\left(\mathrm{X}_{\mathrm{Ci}}, \mathrm{X}_{\mathrm{L}}\right) \\
\text { Subject to: } & \mathrm{dPF}\left(\mathrm{X}_{\mathrm{Ci}}, \mathrm{X}_{\mathrm{L}}\right) \geq 90 \%, \\
& \mathrm{X}_{\mathrm{Ci}} \text { and } \mathrm{X}_{\mathrm{L}} \text { are not a part of }(15) \\
& \mathrm{V}_{\mathrm{C}}\left(\mathrm{X}_{\mathrm{C}}\right) \leq 110 \% \\
& \mathrm{~V}_{\mathrm{CC}}\left(\mathrm{X}_{\mathrm{C}}\right) \leq 120 \sqrt{2} \% .
\end{array}
$$

The simulated results are explicitly demonstrated in Tables IX-XI.

Comparison of the results shows that the general performance of the method is satisfactory, providing improvement of the overall performance compared with Tables VI and VII. Table XI shows that the resultant values come out well within standard limits except cases 3 and 4 . If the resultant values are greater than standard limits, it is a good idea [18] to use 
capacitors with a higher voltage rating. For cases 3 and 4, $6640-\mathrm{V}$ capacitors are used for a $4160-\mathrm{V}$ application. In this case, the limits become 98.8 and 87.77 for $V_{\mathrm{C}}$, and 160.16 and 141.11 for $V_{\mathrm{CC}}$.

Finally, the presented method includes the improvement in the accuracy of the solution and in the ability of it to guarantee convergence to the optimal solutions as illustrated by the examples taken from existing publications.

\section{COMPARISON With Other OBJeCtive FunCtions}

To verify the effectiveness of the proposed LC compensator design approach, a comparison will be made to two published approaches [24], [25].

The approach of [24] is to minimize VTHD on the load by adjusting $X_{C}$ and $X_{L}$ while keeping the $d P F$ constant and construing the cost of the compensating circuit to a series of fixed values. This can be accomplished by minimizing a total cost function $T C$, which represents a combination of VTHD and $C$

$$
\mathrm{TC}=\mathrm{C}_{\mathrm{f}} *(\mathrm{VTHD})^{2}+\mathrm{C}
$$

where $\mathrm{C}_{\mathrm{f}}$ is an arbitrary factor to convert $(V T H D)^{2}$ to cost. Then, the problem becomes

$$
\begin{aligned}
& \text { Minimize } \quad \mathrm{TC}\left(\mathrm{X}_{\mathrm{Ci}}, \mathrm{X}_{\mathrm{L}}\right) \\
& \text { Subject to: } \mathrm{PF}\left(\mathrm{X}_{\mathrm{Ci}}, \mathrm{X}_{\mathrm{L}}\right) \geq 90 \% \\
& \quad \mathrm{X}_{\mathrm{Ci}} \text { and } \mathrm{X}_{\mathrm{L}} \text { are not a part of }(15) .
\end{aligned}
$$

In [25], the objective function to be maximized in the optimal compensation is the profit function $T P$, which can be described as the amount a customer can gain annually by using an $L C$ compensator to reduce the power losses in the supply network while the active power of the load is nearly constant. This quantity is $C$ subtracted from the discount offered by the utility

$$
\mathrm{TP}=\mathrm{C}_{\mathrm{f}} *\left(\mathrm{I}_{\mathrm{S}}^{\mathrm{o}}-\mathrm{I}_{\mathrm{S}}^{2}\right)-\mathrm{C}
$$

where $I_{S}^{o}$ and $I_{S}$ are, respectively, the magnitudes of source current without and with compensation, and $C_{f}$ is the utility discount factor. Then, the problem becomes

$$
\begin{array}{cc}
\text { Minimize } & \mathrm{TP}\left(\mathrm{X}_{\mathrm{Ci}}, \mathrm{X}_{\mathrm{L}}\right) \\
\text { Subject to: } & \mathrm{PF}\left(\mathrm{X}_{\mathrm{Ci}}, \mathrm{X}_{\mathrm{L}}\right) \geq 90 \% \\
& \mathrm{X}_{\mathrm{Ci}} \text { and } \mathrm{X}_{\mathrm{L}} \text { are not a part of }(15) .
\end{array}
$$

The simulated results are explicitly demonstrated in Table XII.

Table XII shows that the general performance of the presented method is satisfactory compared with the other reported methods taken from existing publications.

\section{CONCLUSION}

A method is presented for finding the optimum fixed $L C$ combination to minimize its cost at a load bus while holding the power factor at a desired value and constraining the compensator values which would create resonant conditions and the manufacturers' standard values for power shunt capacitors.

The presented method performs two major tasks: to produce certain level of reactive power, and to provide a low impedance
TABLE XII

COMPARISON OF Simulated RESUlts fOR CASE 1 With DIFFERENT OBJECTIVE FUNCTIONS

\begin{tabular}{l|c|c|c|c}
\hline \hline EQUATION & $Q_{\mathrm{C}}$ & $\mathrm{X}_{\mathrm{L}}^{*}(\Omega)$ & $\mathrm{PF}(\%)$ & $\mathrm{C}(\$)$ \\
\hline$(21)$ & 2700 & 0.3038 & 90.34 & 6758 \\
\hline$(23)$ & 2400 & 0.8279 & 90.99 & 6971 \\
\hline & $\mathrm{I}_{\mathrm{S}}(\mathrm{A})$ & $\mathrm{TL}(\mathrm{kW})$ & $\eta(\%)$ & $\mathrm{dPF}(\%)$ \\
\hline$(21)$ & 767.77 & 6.80 & 99.59 & 92.30 \\
\hline$(23)$ & 761.16 & 6.87 & 99.59 & 91.50 \\
\hline & \multicolumn{2}{|c|}{$\%$ VTHD } & \multicolumn{2}{c}{$\%$ ITHD } \\
\hline$(21)$ & 2.59 & \multicolumn{2}{c}{9.33} \\
\hline$(23)$ & \multicolumn{3}{|c|}{5.24} & \multicolumn{2}{c}{} \\
\hline \hline
\end{tabular}

path for harmonic currents that must be confined. Both requirements listed have a strong impact on the total cost of LC compensator.

The results and examples presented should serve as a guideline only. In practice, the system parameter data may be uncertain. However, the proposed method may still be applied by finding the power factor curves for a variety of system conditions commensurate with those normally encountered and selecting the capacitor and reactor for the best average performance.

Ongoing research effort consists of the modification and application of this method to take into account load profiles, other constraints (for example, the allowable overloads for capacitor imposed by standard or recommendations), and probability density function of several indices as well known in recent international standards; for example, IEC 1000-3-6.

\section{APPENDIX A}

\section{Penalty Function Method Algorithm}

Let the basic optimization problem, with inequality constraints, be of the form (16). This problem is converted into an unconstrained minimization problem by constructing a function of the form

$$
\mathrm{f}\left(\mathrm{X}_{\mathrm{L}}\right)=\mathrm{C}\left(\mathrm{X}_{\mathrm{C}}, \mathrm{X}_{\mathrm{L}}\right)+\sum_{\mathrm{m}} \mu_{\mathrm{m}}\left(\max \left[0, \mathrm{~g}_{\mathrm{m}}\left(\mathrm{X}_{\mathrm{C}}, \mathrm{X}_{\mathrm{L}}\right)\right]\right)
$$

where $g_{m}$ is some function of the constraints, $\mu_{m}$ is a positive constant known as the penalty parameter, and $\max \left[0, g_{m}\left(X_{C}, X_{L}\right)\right]$ is the commonly used form of the penalty parameter, which is the second part of (A.1).

Step 1) Start with an initial feasible point $X_{C}^{0}, X_{L}^{0}$ satisfying all of the constraints with a strict inequality sign. Start with an initial value of $\mu_{1}>0$. Set $J=1$.

Step 2) Minimize $f\left(X_{L}\right)$, (20), by using any of the unconstrained minimization methods and obtain the solution $X_{C}^{*}$, $X_{L}^{*}$. The golden section search method [2] can be applied for obtaining the optimal $X_{L}^{*}$.

Step 3) Test whether the solution $X_{C}^{*}, X_{L}^{*}$ is the optimum solution of the original problem. The algorithm will stop 
when a feasible point will be reached or when the relative change in the objective function is small.

$$
\varepsilon<10^{-6} .
$$

If $X_{C}^{*}, X_{L}^{*}$ is found to be optimum, terminate the process. Otherwise, go to the next step.

Step 4) Find the value of the next penalty parameter as

$$
\mu_{m}^{(J+1)}=\beta \mu_{m}^{(J)}
$$

where $\beta<1$.

Step 5) Set the new value of $J=J+1$, take the new starting point as $X_{C}^{*}, X_{L}^{*}$, and go to step 2 .

\section{REFERENCES}

[1] Y.-M. Chen, "Passive filter design using genetic algorithms," IEEE Trans. Ind. Electron., vol. 50, pp. 202-207, Feb. 2003.

[2] G. van Schoor, J. D. van Wyk, and I. S. Shaw, "Optimal control of a hybrid power compensator using an artificial neural network controller," IEEE Trans. Ind. Applicat., vol. 38, pp. 467-475, Mar./Apr. 2002

[3] C.-J. Chou, C.-W. Liu, J.-Y. Lee, and K.-D. Lee, "Optimal planning of large passive-harmonic-filters set at high voltage level," IEEE Trans. Power Syst., vol. 15, pp. 433-441, Feb. 2000.

[4] J. Y. Choi, S.-H. Rim, and J.-K. Park, "Optimal real time pricing of real and reactive powers," IEEE Trans. Power Syst., vol. 13, pp. 1226-1231, Nov. 1998.

[5] J.-G. Cho, J.-W. Baek, D.-W. Yoo, and H.-S. Lee, "Reduced conduction loss zero-voltage-transition power factor correction converter with low cost," IEEE Trans. Ind. Electron., vol. 45, pp. 395-400, Jun. 1998.

[6] E. M. Mehl and I. Barbi, "An improved high-power factor and low-cost three-phase rectifier," IEEE Trans. Ind. Applicat., vol. 33, pp. 485-492, Mar./Apr. 1997

[7] R. A. Fuselier, "Alternative cost-effective applications of power factor correction," IEEE Trans. Ind. Applicat., vol. 25, pp. 10-18, Jan./Feb. 1989.

[8] M. M. Saied, "Optimal power factor correction," IEEE Trans. Power Syst., vol. 3, pp. 844-851, Aug. 1988.

[9] P. Ziogas, Y. Kang, and V. Stefanovic, "PWM control technique for rectifier filter minimization," IEEE Trans. Ind. Applicat., vol. 21, pp. 1206-1214, Sept./Oct. 1985

[10] — - "Optimum system design of a three-phase rectifier inverter type of frequency changer," IEEE Trans. Ind. Applicat., vol. 21, pp. 1215-1225, Sept./Oct. 1985

[11] N. R. Zargari, G. Joos, and P. D. Ziogas, "Input filter design for PWM current-source rectifiers," IEEE Trans. Ind. Applicat., vol. 30, pp. 1573-1579, Nov./Dec. 1994

[12] V. A. Katic and V. S. Vuckovic, "The effects of distorted supply on PWM rectifier AC filter design," in Proc. PCIM, Nuremberg, Germany, 1992, pp. 219-229.

[13] V. Katic and D. Graovac, "A method for PWM rectifier line side filter optimization in transient and steady states," IEEE Trans. Power Electron., vol. 17, pp. 342-352, May 2002.

[14] M. M. A. Aziz, E. E. A. El-Zahab, and A. F. Zobaa, " $L C$ compensators based on cost minimization for nonlinear loads," in Proc. 2003 Large Engineering Systems Conf. Power Eng., Montreal, QC, Canada, May 7-9, 2003, pp. 143-147.
[15] G. G. Richards, O. T. Tan, P. Klinkhachorn, and N. I. Santoso, "Cost-constrained power factor optimization with source harmonics using $L C$ compensators," IEEE Trans. Ind. Electron., vol. IE-34, pp. 267-270, May 1987

[16] M. M. Abdel-Aziz, E. E. A. El-Zahab, A. M. Ibrahim, and A. F. Zobaa, "Comparing capacitive and $L C$ compensators for power factor correction," in Proc. 10th Int. Conf. Harmonics and Quality of Power, vol. 1, Rio de Janeiro, Brazil, Oct. 6-9, 2002, pp. 42-45.

[17] R. C. Dugan, M. F. McGranaghan, and H. W. Beaty, Electrical Power Systems Quality. New York: Mc-Graw Hill, 1996.

[18] IEEE Guide for Harmonic Control and Reactive Compensation of Static Power Converters, IEEE Std. 519-1981, 1981.

[19] IEEE Standard for Shunt Power Capacitors, IEEE Std. 18-1992, 1992.

[20] D. A. Pierre, Optimization Theory With Applications. New York: Wiley, 1969.

[21] G. H. Hadley, Nonlinear Programming and Dynamic Programming. Reading, MA: Addison-Wesley, 1964.

[22] S. S. Rao, Engineering Optimization: Theory and Practice, 3rd ed. New York: Wiley-Interscience, 1996.

[23] IEEE Recommended Practices and Requirements for Harmonic Control in Electrical Power Systems, IEEE Std. 519-1992, 1992.

[24] R. K. Hartana and G. G. Richards, "Comparing capacitive and LC compensators for power factor correction and voltage harmonic reduction," Elect. Power Syst. Res., vol. 17, pp. 57-64, 1989.

[25] G. G. Richards, P. Klinkhachorn, O. T. Tan, and R. T. Hartana, "Optimal LC compensators for nonlinear loads with uncertain nonsinusoidal source and load characteristics," IEEE Trans. Power Syst., vol. 4, pp. 30-36, Feb. 1989.

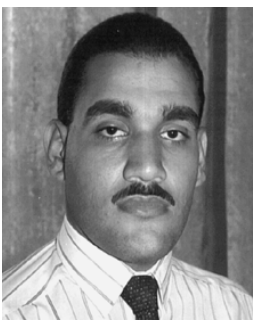

Ahmed Faheem Zobaa (M'01-SM'04) received the B.Sc. (Hons.), M.Sc., and Ph.D. degrees in electrical power and machines from the Faculty of Engineering at Cairo University, Giza, Egypt, in 1992, 1997, and 2002, respectively.

Currently, he is an Assistant Professor in the Department of Electrical Power and Machines with the Faculty of Engineering, Cairo University. He was an Instructor in the Department of Electrical Power and Machines with the Faculty of Engineering at Cairo University from 1992 to 1997, and Teaching Assistant from 1997 to 2002. He is author or co-author of many refereed journal and conference papers. His areas of research include harmonics, compensation of reactive power, power quality, photovoltaics, wind energy, education, and distance learning.

Dr. Zobaa is a member of the IEEE Power Engineering/IEEE Industry Applications/IEEE Industrial Electronics/IEEE Power Electronics Societies, the Institution of Electrical Engineers, and the International Solar Energy Society. He regularly reviews papers for eight IEEE Transactions especially all IEEE/Power Engineering Society transactions and seven journals in his areas of interest. $\mathrm{He}$ is an Editorial Board member for Electric Power Components and Systems Journal and International Journal of Computational Intelligence. He is an Editor of IEEE Power Engineering Letters. Also, he is an Associate Editor for the IEEE TRANSACTIONS ON INDUSTRIAL ELECTRONICS, International Journal of Power and Energy Systems, and International Journal of Power and Energy Systems and International Journal on Modelling and Simulation. 